Journal of mathematics and computer science 8 (2014), 113-127

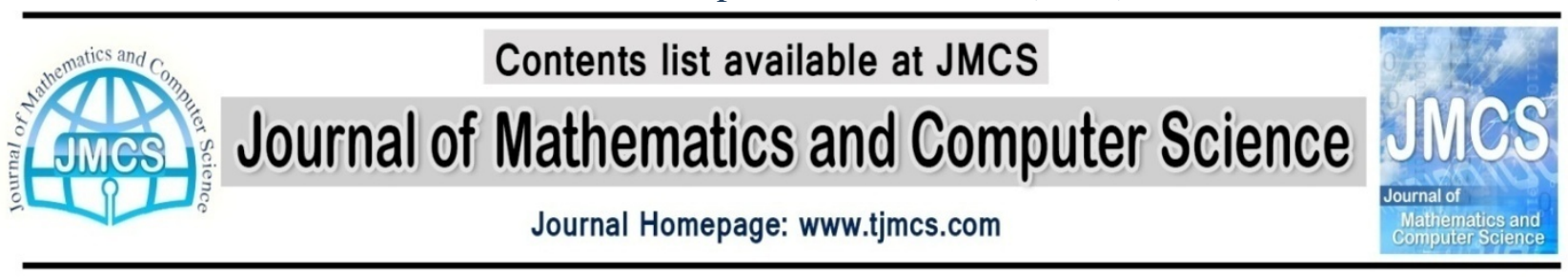

\title{
Intelligent Pitch Controller Identification and Design
}

\author{
Amir Torabi ${ }^{1}$, Amin Adine Ahari ${ }^{1}$, Ali Karsaz ${ }^{1}$, Seyyed Hossin Kazemi ${ }^{1}$ \\ ${ }^{1}$ Faculty of Electrical Engineering, Khorasan University, Mashhad, Iran \\ amirtorabi1@gmail.com
}

\begin{abstract}
Article history:
Received May 2013

Accepted June 2013

Available online June 2013
\end{abstract}

\begin{abstract}
This paper exhibits a comparative assessment based on time response specification performance between modern and classical controller for a pitch control system of an aircraft system. The dynamic modeling of pitch control system is considered on the design of an autopilot that controls the pitch angle. It starts with a derivation of a suitable mathematical model to describe the dynamics of an aircraft. For getting close to actual conditions the white noise disturbance is applied to the system. In this paper, it is assumed that the model pitch control system is not available. So using the identification system and Box-Jenkins model estimator we identify the pitch control system. System's identification is a procedure for accurately characterizing the dynamic response behavior of a complete aircraft, of a subsystem, or of an individual component from measured data. To study the effectiveness of the controllers, the LQR Controller and PID Controller and fuzzy controller is developed for controlling the pitch angle of an aircraft system. Simulation results for the response of pitch controller are presented instep's response. Finally, the performances of pitch control systems are investigated and analyzed based on common criteria of step's response in order to identify which control strategy delivers better performance with respect to the desired pitch angle. It is found from simulation that the fuzzy controller gives the best performance compared to PID and LQR controller.
\end{abstract}

Keywords- Aircraft Pitch Controller, Fuzzy Controller, PID,LQR,System Identification

\section{INTRODUCTION}

Today's aircraft designs rely heavily on automatic control system to monitor and control many of aircraft's subsystem. The development of automatic control system has played an important role in the growth of civil and military aviation. For this situation an autopilot is designed that controls the pitch of aircraft that can be used by the flight crew to lessen their workload during cruising and help them land their aircraft during adverse weather condition in the real situation. Pitch is controlled by the rear part of the tail plane's horizontal stabilizer being hinged to create an elevator. The pitch angle of an aircraft is controlled by adjusting the angle and therefore the lift force of the rear elevator. The aerodynamic forces (lift and drug) as 
well as the aircraft's inertia are taken into account. This is a third order, nonlinear system which is linearized about the operating point [1].

To reduce the complexity of analysis, the aircraft is usually assumed as a rigid body and aircraft's motion consists of a small deviation from equilibrium flight condition [2].The pitch of aircraft is controlled by an elevator which is usually situated at the rear of the airplane running parallel to the wing that houses the ailerons. Pitch control is a longitudinal problem, and this work gives on design an autopilot that controls the pitch of an aircraft. Autopilot is a pilot relief mechanism that assists in maintaining an attitude, heading, altitude or flying to navigation or landing references [3].

The combination of nonlinear dynamics, modeling uncertainties and parameter variation in characterizing an aircraft and its operating environment are the major problem of flight control system. This work attempts to survey the control strategies required to address the complex longitudinal dynamic characteristics of such aircraft. Many research works have reported on controlling the pitch or longitudinal dynamic of an aircraft for the purpose of flight stability [4], [5], [6], [7] and [8]. This research is still remaining an open issue in the present and future efforts [9].

Recently, the design of controllers to achieve a non-overshooting response has been investigated for linear systems. However, for an aircraft with conventional aerodynamic configuration, it is actually not easy to design a controller that is capable of driving the pitch angle (with a possible non-zero initial value) to asymptotically track the reference without overshooting. The linearized mathematical model of the pitchangle dynamics, using elevator to control pitch angle, is of third order[13].

In this paper we have used fuzzy controller to improve performance system. In the past paper, disturbance effect hasn't been applied before to system but in this paper it applied. The simulation results shown that the dynamic characteristics of control systems can be improved by this method.

\section{PROBLEM STATEMENT}

Control of dynamic systems with present-day sophistication and complexities has often been an important research area due to the difficulties in modeling, nonlinearities, and uncertainties, particularly when there is a constant change in system dynamics. It is also known that the response of a dynamic nonlinear plant cannot be tracked into a desired pattern with a linear controller. Thus, a changing dynamic controller is important to control such a plant [10].

Pitch is defined as a rotation around the lateral or transverse axis, which is parallel to the wings, and is measured as the angle between the direction of speed in a vertical plan and the horizontal line. Changes of pitch are caused by the deflection of the elevator, which rises or lowers the nose and tail of the aircraft. When the elevator is raised (defined as negative value), the force of the airflow will push the tail down. Hence, the nose of the aircraft will rise and the altitude of the aircraft will increase. One of the targets of a pitch control system is to control or help a pilot to control an aircraft to keep the pitch attitude constant, that is, make the aircraft return to desired attitude in a reasonable length of time after a disturbance of the pitch angle, or make the pitch follow a given command as quickly as possible [11].

\section{ROBUST STABILITY OF NONLINEAR SYSTEMS}

We consider the nonlinear dynamics of the pitch axis of a fictitious Aircraft the Robust Aircraft Model. The state space is given by $\left[\begin{array}{lllll}\qquad & v & \alpha\end{array}\right]^{T}$, which stand for the pitch rate $(\mathrm{rad} / \mathrm{s})$, velocity $(\mathrm{m} / \mathrm{s})$, angle of attack ( $\left.\mathrm{rad}\right)$ and pitch angle (rad), respectively. The control inputs are $\left.{ }_{\delta_{e}} \delta_{I H}\right]$, which stand for the elevator deflection (rad) and throttle lever deflection ( $\mathrm{rad})$, respectively. The throttle input is help at a constant trim and is not dynamically 
varied. We designed a LTI dynamic inversion based control law for the short period dynamics of the pitch axis at a particular trig configuration which is given by a particular flight condition [12].

\section{Modelling of a Pitch Control}

This section provides a brief description on the modelling of pitch control longitudinal equation of aircraft, as a basis of a simulation environment for development and performance evaluation of the proposed controller techniques. The system of longitudinal dynamics is considered in this investigation and derived in the transfer function and states pace forms. The pitch control system considered in this work is shown in Figure 1 where $X_{b}, Y_{b}$ and $Z_{b}$ represent the aerodynamics force components. $\theta, \Phi$ and $\delta_{e}$ represent the orientation of aircraft (pitch angle) in the earth-axis system and elevator deflection angle.

The equations governing the motion of an aircraft are a very complicated set of six nonlinear coupled differential equations. Although, under certain assumptions, they can be decoupled and linearized into longitudinal and lateral equations. Aircraft pitch is governed by the longitudinal dynamics. In this example we will design an autopilot that controls the pitch of an aircraft. The basic coordinate axes and forces acting on an aircraft are shown in the figure given below.

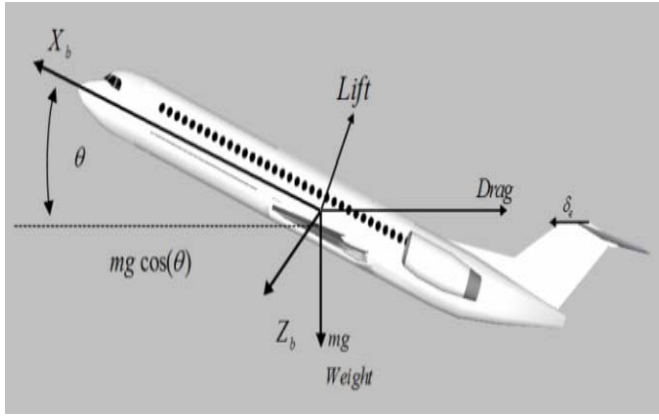

Fig. 1 Description of pitch control system

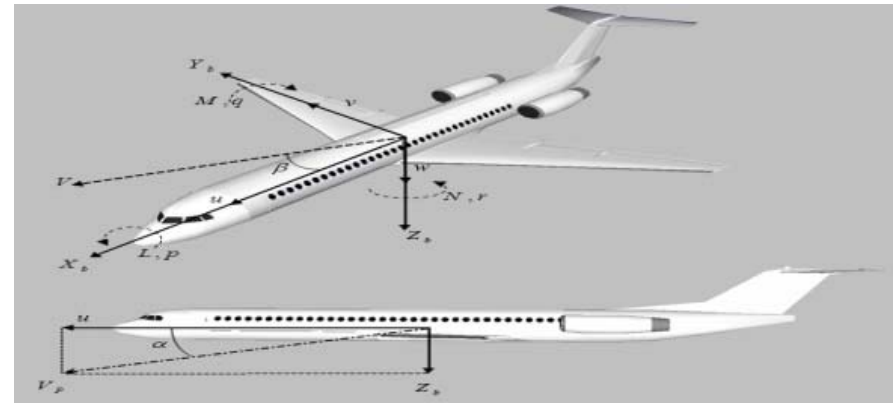

Fig. 2 Definition of force, moments and velocity

in body fixed coordinate

Figure 2 shows the forces, moments and velocity components in the body fixed coordinate of aircraft system. The aerodynamics moment components for roll, pitch and yaw axis are represent as $L, M$ and $N$. The term $p$, $q, r$ represent the angular rates about roll, pitch and yaw axis while term $u, v, w$ represent the velocity components of roll, pitch and yaw axis. $\alpha$ and $\beta$ represent as the angle of attack and sideslip.

A few assumption need to be considered before continuing with the modeling process. First, the aircraft is steady state cruise at constant altitude and velocity, thus the thrust and drag are cancel out and the lift and weight balance out each other. Second, the change in pitch angle does not change the speed of an aircraft under any circumstance.

TABLE 1. LONGITUDINAL DERIVATIVE STABILITY PARAMETERS

\begin{tabular}{c} 
Components \\
\hline Dynamics Pressure and Dimensional \\
Derivative \\
$\mathrm{Q}=36.8 \mathrm{lb} / \mathrm{ft}^{2}, \mathrm{QS}=6771 \mathrm{lb}$, \\
$\mathrm{QS} \mathrm{c}=38596 \mathrm{ft} . \mathrm{lb},\left(\mathrm{c} / 2 \mathrm{u}_{0}\right)=0.016 \mathrm{~s}$ \\
\hline
\end{tabular}




\begin{tabular}{cccc}
\cline { 2 - 4 } & $\begin{array}{c}\text { Z-Force, } \\
\left(\mathrm{F}^{-1}\right)\end{array}$ & $\begin{array}{c}\text { Pitching } \\
\text { Moment, } \\
\left(\mathrm{FT}^{-1}\right)\end{array}$ & $\begin{array}{c}\text { Pitching } \\
\text { Moment, } \\
\left(\mathrm{FT}^{-1}\right)\end{array}$ \\
\hline $\begin{array}{c}\text { Rolling } \\
\text { velocitie } \\
\text { s }\end{array}$ & $X_{u}=-0.045$ & $Z_{u}=-0.369$ & $M_{u}=-0.369$ \\
$\begin{array}{c}\text { Yawing } \\
\text { velocitie }\end{array}$ & $X_{W}=0.036$ & $Z_{W}=-2.02$ & $M_{W}=-0.05$ \\
S & $X_{W}=0$ & $X_{\dot{W}}=0$ & $M_{\dot{W}}=0$ \\
Angle of & $X_{\alpha}=0$ & $Z_{\alpha}=-355.42$ & $M_{\alpha}=-8.8$ \\
attack & $X_{\dot{\alpha}}=0$ & $Z_{\dot{\alpha}}=0$ & $M_{\dot{\alpha}}=-0.8976$ \\
$\begin{array}{c}\text { Pitching } \\
\text { rate }\end{array}$ & $X_{a}=0$ & $Z_{a}=0$ & $M_{a}=-2.05$ \\
$\begin{array}{c}\text { Elevator } \\
\text { deflectio } \\
\mathrm{n}\end{array}$ & $X_{\delta_{e}}=0$ & $Z_{\delta_{e}}=-28.15$ & $M_{\delta_{e}}=-11.874$ \\
\hline
\end{tabular}

Referring to the Figure 1 and Figure 2, the following dynamic equations include force and moment equations are determined as shown in Equations (1), (2) and (3). Referring to the Figure 1 and Figure 2, the following dynamic equations include force and moment equations are determined. The longitudinal stability derivatives parameter used are denoted in Table $1^{[1]}$.

$\mathrm{X}-\mathrm{mgs}_{\theta}=\mathrm{m}(\dot{\mathrm{u}}+\mathrm{qv}-\mathrm{rv})$

(1)

$\mathrm{Z}+\mathrm{mgC}_{\theta} \mathrm{C}_{\phi}=\mathrm{m}(\dot{\mathrm{w}}+\mathrm{pv}-\mathrm{qv})$

(2)

$\mathrm{M}=\mathrm{I}_{\mathrm{y}} \dot{\mathrm{q}}+\mathrm{rq}\left(\mathrm{I}_{\mathrm{X}}-\mathrm{I}_{\mathrm{Z}}\right)+\mathrm{I}_{\mathrm{XZ}}\left(\mathrm{p}^{2}-\mathrm{r}^{2}\right)$

(3)

It is required to completely solved the aircraft problem with considering the following assumption: (1) rolling rate $\rho=\dot{\Phi}-\dot{\psi} S_{\theta}$, (2) yawing rate, $q=\dot{\theta} C_{\Phi}+\dot{\psi} C_{\theta} S_{\Phi}$, (3)pitching rate, $r=\dot{\psi} C_{\theta} C_{\Phi}-\dot{\theta} S_{\Phi}$, (4) Pitch Angle, $\dot{\theta}=\mathrm{qC}_{\Phi}-\mathrm{rS}_{\Phi}$, (5) roll Angle, $\dot{\Phi}=\mathrm{p}+\mathrm{qS}_{\Phi} \mathrm{T}_{\theta}+\mathrm{rC}_{\Phi} \mathrm{T}_{\theta}$ and (6) Yaw Angle, $\dot{\psi}=\left(\mathrm{qS}_{\Phi}+\mathrm{r}_{\Phi}\right) \sec \theta$.

Equation (1), (2) and (3) should be linearized using small disturbance theory. The equations are replaced by a variables or reference value plus a perturbation or disturbance, as shown below.

$\begin{array}{ccc}\mathrm{u}=\mathrm{u}_{0}+\Delta \mathrm{u} & \mathrm{v}=\mathrm{v}_{0}+\Delta \mathrm{u} & \mathrm{W}=\mathrm{w}_{0}+\Delta \mathrm{w} \\ \mathrm{p}=\mathrm{p}_{0}+\Delta \mathrm{p} & \mathrm{q}=\mathrm{q}_{0}+\Delta \mathrm{q} & \mathrm{r}=\mathrm{r}_{0}+\Delta \mathrm{r} \\ \mathrm{X}=\mathrm{X}_{0}+\Delta \mathrm{X} & \mathrm{M}=\mathrm{M}_{0}+\mathrm{MY} & \mathrm{Z}=\mathrm{Z}_{0}+\Delta \mathrm{Z}\end{array}$

$\delta=\delta_{0}+\Delta \delta$

For convenience, the reference flight condition is assumed to be symmetric and the propulsive forces are assumed to remain constant. This implies that, $\mathrm{v}_{0}=\mathrm{p}_{0}=\mathrm{q}_{0}=\mathrm{r}_{0}=\phi_{0}=\mathrm{w}_{0}=0$. After linearization the (4), (5) and (6) are obtained.

$$
\left(\frac{\mathrm{d}}{\mathrm{dt}}-\mathrm{X}_{\mathrm{u}}\right) \Delta \mathrm{u}-\mathrm{X}_{\mathrm{w}} \Delta \mathrm{w}+\left(\mathrm{g} \cos \theta_{0}\right) \Delta \theta=\mathrm{X} \delta_{\mathrm{e}} \Delta \delta_{\mathrm{e}}
$$

(4)

(5)

$$
-\mathrm{Z}_{\mathrm{u}} \Delta \mathrm{u}+\left[\left(1-\mathrm{Z}_{\mathrm{u}}\right) \frac{\mathrm{d}}{\mathrm{dt}}-\mathrm{Z}_{\mathrm{w}}\right] \Delta \mathrm{w}-\left[\left(\mathrm{u}_{0}-\mathrm{Z}_{\mathrm{q}}\right) \frac{\mathrm{d}}{\mathrm{dt}}-\sin \theta_{0}\right] \Delta \theta=\mathrm{Z}_{\delta \mathrm{e}} \Delta \delta_{\mathrm{e}}
$$$$
-\mathrm{M}_{\mathrm{u}} \Delta \mathrm{u}-\left(\mathrm{M}_{\mathrm{w}} \frac{\mathrm{d}}{\mathrm{dt}}+\mathrm{M}_{\mathrm{w}}\right) \Delta \mathrm{w}+\left(\frac{\mathrm{d}^{2}}{\mathrm{~d}^{2} \mathrm{t}}-\mathrm{M}_{\mathrm{q}} \frac{\mathrm{d}}{\mathrm{dt}}\right) \Delta \theta=\mathrm{M}_{\delta \mathrm{e}} \Delta \delta_{\mathrm{e}}
$$ 
By manipulating the (4), (5), (6) and substituting the parameters values of the longitudinal stability derivatives, the following transfer function for the change in the pitch rate to the change in elevator deflection angle is shown as (7) obtained:

$$
\frac{\Delta \mathrm{q}(\mathrm{s})}{\Delta \delta_{\mathrm{e}}(\mathrm{s})}=\frac{-\left(\mathrm{M}_{\delta \mathrm{e}}+\mathrm{M}_{\dot{\alpha}} \mathrm{Z}_{\delta \mathrm{e}} / \mathrm{u}_{0}\right) \mathrm{s}-\left(\mathrm{M}_{\alpha} \mathrm{Z}_{\delta \mathrm{e}} / \mathrm{u}_{0}-\mathrm{M}_{\alpha} \mathrm{Z}_{\alpha} / \mathrm{u}_{0}\right)}{\mathrm{s}^{2}-\left(\mathrm{M}_{\mathrm{q}}+\mathrm{M}_{\dot{\alpha}}+\mathrm{Z}_{\alpha} / \mathrm{u}_{0}\right) \mathrm{s}+\left(\mathrm{Z}_{\alpha} \mathrm{M}_{\alpha} / \mathrm{u}_{0}-\mathrm{M}_{\alpha}\right)}
$$

The transfer function of the change in pitch angle to the change in elevator angle can be obtained from the change in pitch rates to the change in elevator angle in the following way:

(8)

$$
\Delta \mathrm{q}=\Delta \dot{\theta}
$$

$$
\Delta \mathrm{q}(\mathrm{s})=\mathrm{s} \Delta \theta(\mathrm{s})
$$

(9)

$$
\frac{\Delta \theta(\mathrm{s})}{\Delta \delta_{\mathrm{e}}(\mathrm{s})}=\frac{1}{\mathrm{~s}} \cdot \frac{\Delta \mathrm{q}(\mathrm{s})}{\Delta \theta(\mathrm{s})}
$$

(10)

Therefore the transfer function of the pitch control system is obtained in (11) and (12) respectively:

$\frac{\Delta \mathrm{q}(\mathrm{s})}{\Delta \delta_{\mathrm{e}}(\mathrm{s})}=\frac{1}{\mathrm{~s}} \cdot \frac{-\left(\mathrm{M}_{\delta \mathrm{e}}+\mathrm{M}_{\dot{\alpha}} \mathrm{Z}_{\delta \mathrm{e}} / \mathrm{u}_{0}\right) \mathrm{s}-\left(\mathrm{M}_{\alpha} \mathrm{Z}_{\delta \mathrm{e}} / \mathrm{u}_{0}-\mathrm{M}_{\alpha} \mathrm{Z}_{\alpha} / \mathrm{u}_{0}\right)}{\mathrm{s}^{2}-\left(\mathrm{M}_{\mathrm{q}}+\mathrm{M}_{\dot{\alpha}}+\mathrm{Z}_{\alpha} / \mathrm{u}_{0}\right) \mathrm{s}+\left(\mathrm{Z}_{\alpha} \mathrm{M}_{\alpha} / \mathrm{u}_{0}-\mathrm{M}_{\alpha}\right)}$

\section{Transfer function}

To find the transfer function of the above system, we need to take the Laplace transform of the above modeling equations. Recall that when finding a transfer function, zero initial conditions should be assumed. The Laplace transform of the above equations are shown below[19]:

$$
\frac{\Delta \theta(\mathrm{s})}{\Delta \delta_{\mathrm{e}}(\mathrm{s})}=\frac{1.151 \mathrm{~s}+0.1774}{\mathrm{~s}^{3}+0.739 \mathrm{~s}^{2}+0.921 \mathrm{~s}}
$$

These values are taken from the data from one of Boeing's commercial aircraft.The transfer function can be represented in state-space form and output equation as state by (13) and (14).

(13)

$$
\left[\begin{array}{c}
\Delta \dot{\alpha} \\
\Delta \dot{\mathrm{q}} \\
\Delta \dot{\theta}
\end{array}\right]=\left[\begin{array}{ccc}
-0.313 & 56.7 & 0 \\
-0.0139 & -0.426 & 0 \\
0 & 56.7 & 0
\end{array}\right]\left[\begin{array}{l}
\Delta \alpha \\
\Delta \mathrm{q} \\
\Delta \theta
\end{array}\right]+\left[\begin{array}{c}
0.232 \\
0.0203 \\
0
\end{array}\right]\left[\Delta_{\delta \mathrm{e}}\right]
$$

Since our output is pitch angle, the output equation is the following.

$$
\mathrm{y}=\left[\begin{array}{lll}
0 & 0 & 1
\end{array}\right]\left[\begin{array}{c}
\Delta \alpha \\
\Delta \mathrm{q} \\
\Delta \theta
\end{array}\right]+
$$

\section{LQR Controller}

LQR is a method in modern control theory that used state-space approach to analyze such a system. Using state space methods it is relatively simple to work with a multi-output system. The system can be stabilized using full-state feedback system.

In designing LQR controller, lqr function in Matlab can be used to determine the value of the vector $\mathrm{K}$ which determined the feedback control law. This is done by choosing two parameter values, input $\mathrm{R}=1$ and $Q=C T \times C$ 
where $\mathrm{CT}$ is the matrix transpose of $\mathrm{C}$ from state equation. The controller can be tuned by changing the

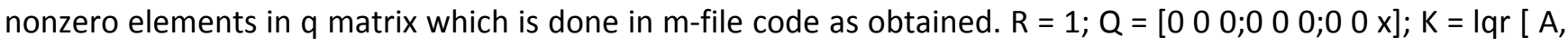
$B, Q, R]$. Consequently, by tuning the value of $x=500$, the following values of matrix $K$ are obtained. If $x$ is increased even higher, improvement to the response should be obtained even more. Although for this case, the Values of $x=500$ is chosen because it satisfied the design requirements while keep $x$ as small as possible. Matrix $\mathrm{K}=[-0.57041 .692922 .3607]$ In order to reduce steady state error of the system Output, a value of constant gain Nbar should be added after the reference [14].

Simulation LQR controller for pitch system is shown in Figure 3.

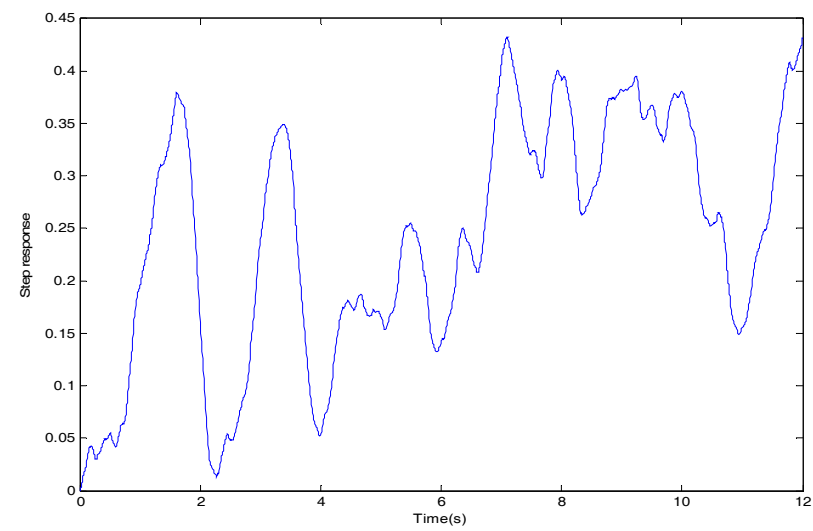

Fig. 3 Step response LQR controller for pitch system with apply white noise to system

\section{THE PRINCIPLE OF PID CONTROLLER}

The PID controller is often described in the following transfer equation.

PID control is the proportion of error (P), integral of error (I), differential of error (D) control. In the analog control system, the analog PID control system is showed in Fig. 4. The system is consisted of analog PID controller and the controlled plant[15].

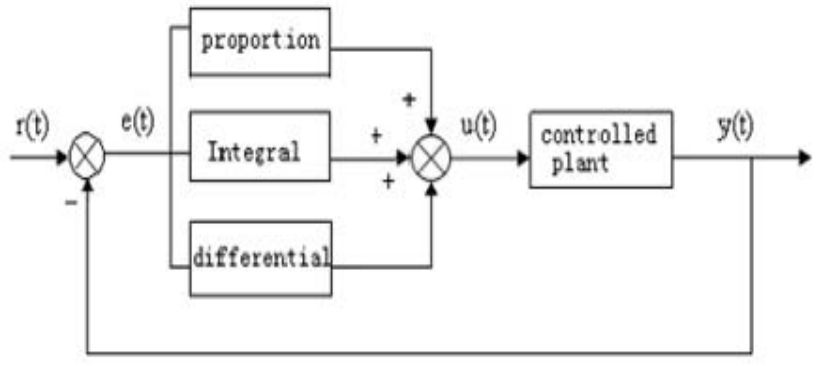

Fig. 4 The analog PID controller [15]

PID controller is a linear controller, the error is Obtained by the given value of $r(t)$ and the actual output $y(r)$.

(15)

$\mathrm{e}(\mathrm{t})=\mathrm{r}(\mathrm{t})-\mathrm{y}(\mathrm{t})$

The control value is gained by composing linearly the proportion and integral and differential of the error, which control the controlled plant, so it is called as PID controller. The deviation of the ratio of integral and differential control, through a linear combination of composition control the amount of control on the plant, it said the PID controller. The control law is as follows: ${ }^{[11]}$ 
(16)

Where $\mathrm{Kp}$ is the proportional factor; $\mathrm{KI}$ is the integral factor; $\mathrm{KD}$ is the differrential factor; $\mathrm{e}(\mathrm{k})$ is the speed error; and ec(k) is the change rate of its speed [16].

Simulation PID controller for pitch system is shown in Figure 5.

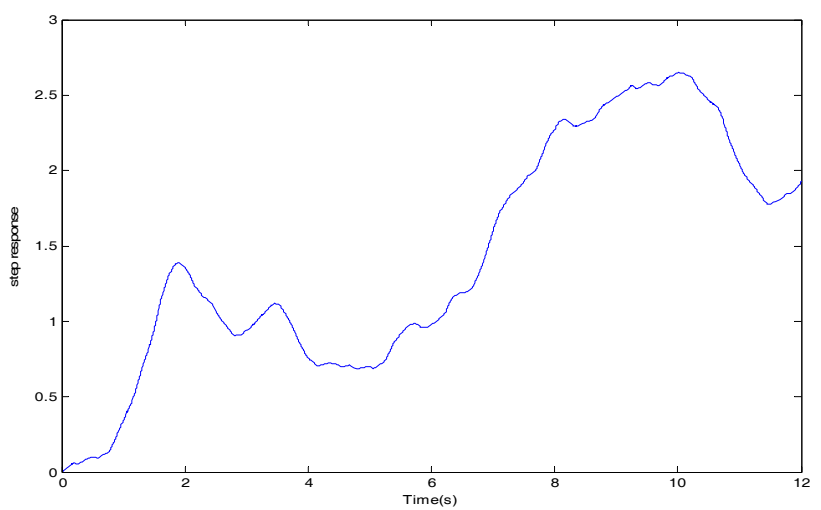

Fig. 5 Step response PID controller for pitch system with apply white noise to system.

\section{THE DESIGN OF FUZZY CONTROLLER}

Fuzzy control is based on the artificial experience. Therefore, for those control problem which can't be resolved by traditional methods can often be resolved by the fuzzy control technology. By the fuzzy control technology, it does not know the mathematical model of the plant and easy to control uncertain systems or nonlinear control systems and can restrain the strong disturbance. The basic structure of fuzzy control system shown in Figure 6.

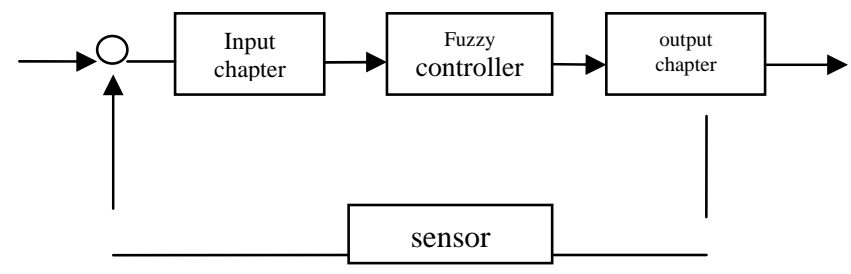

Fig. 6 The basic structure of fuzzy control system [15].

The only difference is to control the device by fuzzy controller to achieve the desired performance. Fuzzy selftuning PID controller is a conventional PID regulator based on the fuzzy set theory, under the absolute control error and deviation change and the absolute value of the rate, on-line automatically adjusting the proportional coefficient KP, integral coefficient of $\mathrm{KI}$ and differential factor KD of the fuzzy controller. Fuzzy controller is a nonlinear control device, using fuzzy reasoning algorithm. The sample data of the controlled process are taken as the clear amount of input to the controller, and then after input quantization factor calculation, are transferred into fuzzy values, so they can be used for fuzzy reasoning by fuzzy language and rules.

To the other part of process, the reasoning results are firstly transferred into clear values by anti-fuzzy inference and thus derive the control output with quantified factor calculation used as the control value for the controlled process. Based on the MATLAB fuzzy logic toolbox, the above control algorithm can be easily implemented [16]. 


\section{DESIGN OF NOMINAL FUZZY CONTROLLER}

In order to design the PID parameters based-on fuzzy controller, at first the simplest structure of two-input single output nominal fuzzy controller is given. At any given time instance $n$ with a sampling time Ts, the two input variables of fuzzy controller, error state variable and error change are defined as

$e(n)=y(n)-r(n)$

$\Delta e(n)=e(n)-e(n-1)$

And its output variable $u(n)$ is the control signal of process.

Without loss the generality, the system is assumed to have $r$ inputs denoted by the $r$-dimensional vector $\mathrm{U}(\mathrm{kT})=\left[\mathrm{u}_{1}(\mathrm{kT}) \ldots \mathrm{u}_{\mathrm{r}}(\mathrm{kT})\right]^{\top}$ and $\mathrm{s}$ outputs denoted by the $\mathrm{s}$-dimensional vector $\mathrm{y}(\mathrm{kT})=\left[\mathrm{y}_{1}(\mathrm{kT})-\mathrm{y}_{\mathrm{s}}(\mathrm{k} T)\right]^{\top}$. Most often the inputs to the fuzzy controller are generated by some function of the plant output $\mathrm{y}(\mathrm{Kt})$ and reference input $y_{r}(k T)$. The inputs to the fuzzy controller are the error $e(k T)=\left[e_{1}(k T) \ldots e_{s}(k T)\right]^{\prime}$ and changes in error $c(k T)$ $=\left[C_{i}(k T) \quad \ldots C_{s}(k T)\right]^{\top}$ defined as

$\mathrm{e}(\mathrm{kT})=\mathrm{y}_{\mathrm{r}}(\mathrm{kT})-\mathrm{y}(\mathrm{kT})$

$c(k T)=\frac{y r(k T)-y(k T)}{T}$

Where $\mathrm{e}(\mathrm{kT})=\mathrm{y}_{\mathrm{r}}(\mathrm{kT})-\mathrm{y}(\mathrm{kT})$ denotes the desired plant output, $\mathrm{T}$ is sample period.

For greater flexibility in fuzzy controller implementation, the universes of discourse for each plant input are normalized to the interval $\left[\begin{array}{ll}-1 & 1\end{array}\right]$ by means of constant scaling factors. The gains $g_{e}, g_{c}$ and $g_{u}$ were employed to normalize the universe of discourse for the error $e(k T)$ and changes in error $c(k T)$, and controller output $\mathrm{u}(\mathrm{kT})$ respectively.

With the plant input is generated from IF-THEN control rules of the form

If $\widetilde{\mathrm{e}}$ is $\widetilde{\mathrm{E}}_{\mathrm{i}}$ and $\widetilde{\mathrm{c}}$ is $\widetilde{\mathrm{C}}_{\mathrm{j}}$ then $\widetilde{\mathrm{u}}$ is $\widetilde{\mathrm{U}}_{\mathrm{l}}$

Where $\widetilde{\mathrm{e}}$ and $\tilde{\mathrm{c}}$ denote the linguistic variables associated with controller inputs e and c respectively. $\widetilde{u}$ denotes the linguistic variable associated with the controller output $u, \widetilde{E}_{i}$ and $\widetilde{C}_{j}$ denote the linguistic values respectively and $\breve{U}_{1}$ denotes the consequent linguistic value [17] .These are 49 rules that have been utilized as a closed-loop component in designing the FLC for maintaining pitch angle of aircraft system as defined in Table 2 [7].

TABLE 2. FUZZY CONTROL RULES

\begin{tabular}{|c|c|c|c|c|c|c|c|}
\hline$e / \Delta e$ & $\mathrm{NL}$ & $\mathrm{N}$ & $\mathrm{NS}$ & $\mathrm{ZR}$ & $\mathrm{PS}$ & $\mathrm{PM}$ & $\mathrm{PL}$ \\
\hline $\mathrm{PL}$ & $\mathrm{NS}$ & $\mathrm{ZR}$ & $\mathrm{PS}$ & $\mathrm{PM}$ & $\mathrm{PL}$ & $\mathrm{PL}$ & $\mathrm{PL}$ \\
\hline $\mathrm{PS}$ & $\mathrm{N}$ & $\mathrm{NS}$ & $\mathrm{ZR}$ & $\mathrm{PS}$ & $\mathrm{PM}$ & $\mathrm{PL}$ & $\mathrm{PL}$ \\
\hline $\mathrm{MR}$ & $\mathrm{NL}$ & $\mathrm{N}$ & $\mathrm{NS}$ & $\mathrm{ZR}$ & $\mathrm{PS}$ & $\mathrm{PM}$ & $\mathrm{PL}$ \\
\hline $\mathrm{NS}$ & $\mathrm{NL}$ & $\mathrm{NL}$ & $\mathrm{N}$ & $\mathrm{NS}$ & $\mathrm{ZR}$ & $\mathrm{PS}$ & $\mathrm{PM}$ \\
\hline $\mathrm{NM}$ & $\mathrm{NL}$ & $\mathrm{NL}$ & $\mathrm{NL}$ & $\mathrm{N}$ & $\mathrm{NS}$ & $\mathrm{ZR}$ & $\mathrm{PS}$ \\
$\mathrm{NL}$ & $\mathrm{NL}$ & $\mathrm{NL}$ & $\mathrm{NL}$ & $\mathrm{NL}$ & $\mathrm{N}$ & $\mathrm{NS}$ & $\mathrm{ZR}$ \\
\hline
\end{tabular}

\section{IMPLEMENTATION AND RESULTS}


The membership functions for error and Control surface of fuzzy are shown as Figs. 7 and 8 respectivly.

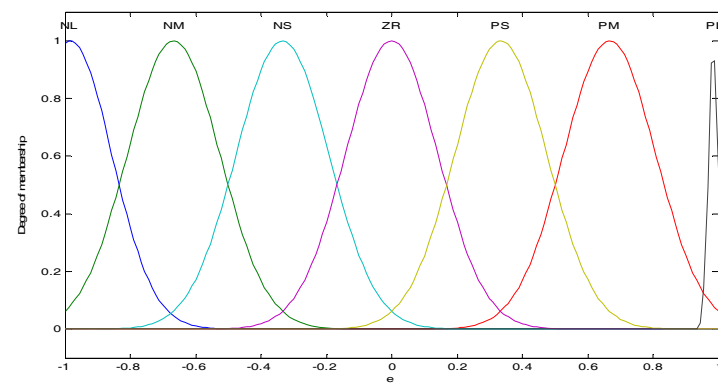

Fig. 7 Membership function of input e and $\Delta e$ controller proposed

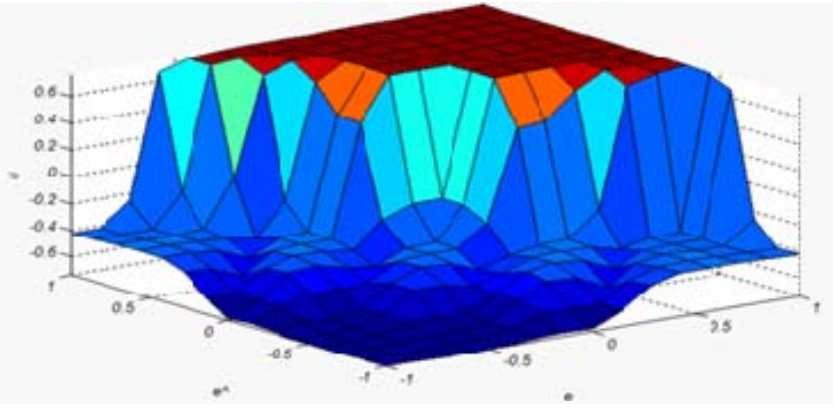

Fig. 8 Control surface of fuzzy logic

\section{System Identification}

System identification is a procedure for accurately chara-cterizing the dynamic response behavior of a complete aircraft, subsystem, or individual component from measured data. This key technology for modern fly-by-wire flight control system development and integration provides unified flow of information regarding system performance around the entire life cycle from specification and design through development and flight test.

Dynamic models of expected system behavior are determined in the design process using system identification and are tracked and updated all over the aircraft development and flight testing. System identification provides an accurate, rapid, and reliable approach for defining design specifications and for validating aircraft flight performance for highly-augmented flight-control systems [18].

\section{BOX-JENKINS}

The Box-Jenkins model belongs to the class of output error models. It's an OE model with additional degrees of freedom for the noise model. While the OE model assumes an additive white disturbance at the process output, the BJ allows any colored disturbance. It may be generated by filtering white noise through a linear filter with arbitrary numerator and denominator. The BJ model is depicted in Figure 9, and is described by

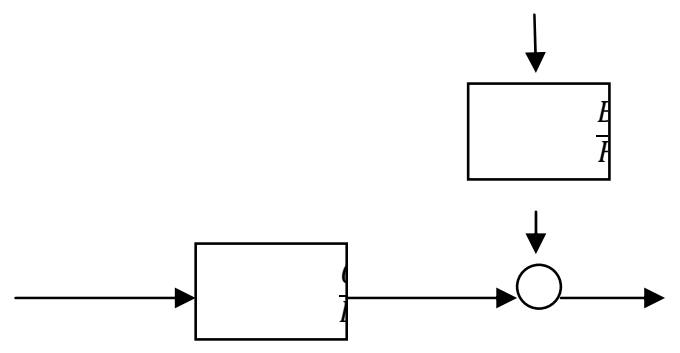

Fig.9 Box-Jenkins model

$\mathrm{y}(\mathrm{k})=\frac{\mathrm{B}(\mathrm{q})}{\mathrm{F}(\mathrm{q})} u(k)+\frac{C(q)}{D(q)} v(k)$

Thus, The BJ model can be seen as the output error class counterpart of the ARARMAX model, which belongs to the equation error class. For the equation error models the special case $D(q)=1$ corresponds to the $A R M A X$ model and the special case $C(q)=1$ corresponds to the ARARX model. These special cases for the BJ model do not have specific names. For $C(q)=D(q)$ the $B J$ simplifies to the OE model. Note that the BJ model can imitate all equation error models if the order of the noise model is high enough. Then the denominator of the noise model $D(q)$ may 
(but of course does not have to)include the process denominator dynamics $F(q)$. Of all linear models the BJ model is the most general and flexible. It allows one to estimate separate transfer function with arbitrary numerators and denominators from the input to the output and from the disturbance to the output. However, on the other hand flexibility of the BJ model requires one to estimate a large number of parameters. For most applications this is either not worth the price or not possible owing to data set that are too small and noisy. The optimal BJ predictor is

$\hat{y}(k \mid k-1)=\frac{B(q) D(q)}{F(q) C(q)} u(k)+\frac{C(q)-D(q)}{C(q)}$

(22)

Note that the notation " $\mid \mathrm{k}-1$ " cannot be discarded as for the OE model because the optimal prediction of a BJ model utilize previous process outputs in order to extract the information contained in the correlated disturbance $n(k)=C(q) / D(q) v(k)$.

$e(k)=\frac{D(q)}{C(q)} y(k)+\frac{B(q) D(q)}{F(q) C(q)} u(k)$

Typically, a BJ model is estimate by nonlinear optimization, where first an ARX model is estimated in order to determine the initial parameter. Model noise estimated:

$Z^{2}+0.28878 z+0.12677$

$Z^{2}-1.8361 z+0.83334$

(24)

In Fig.10 estimation results are presented.Actual output is blue and simulated model output is red.
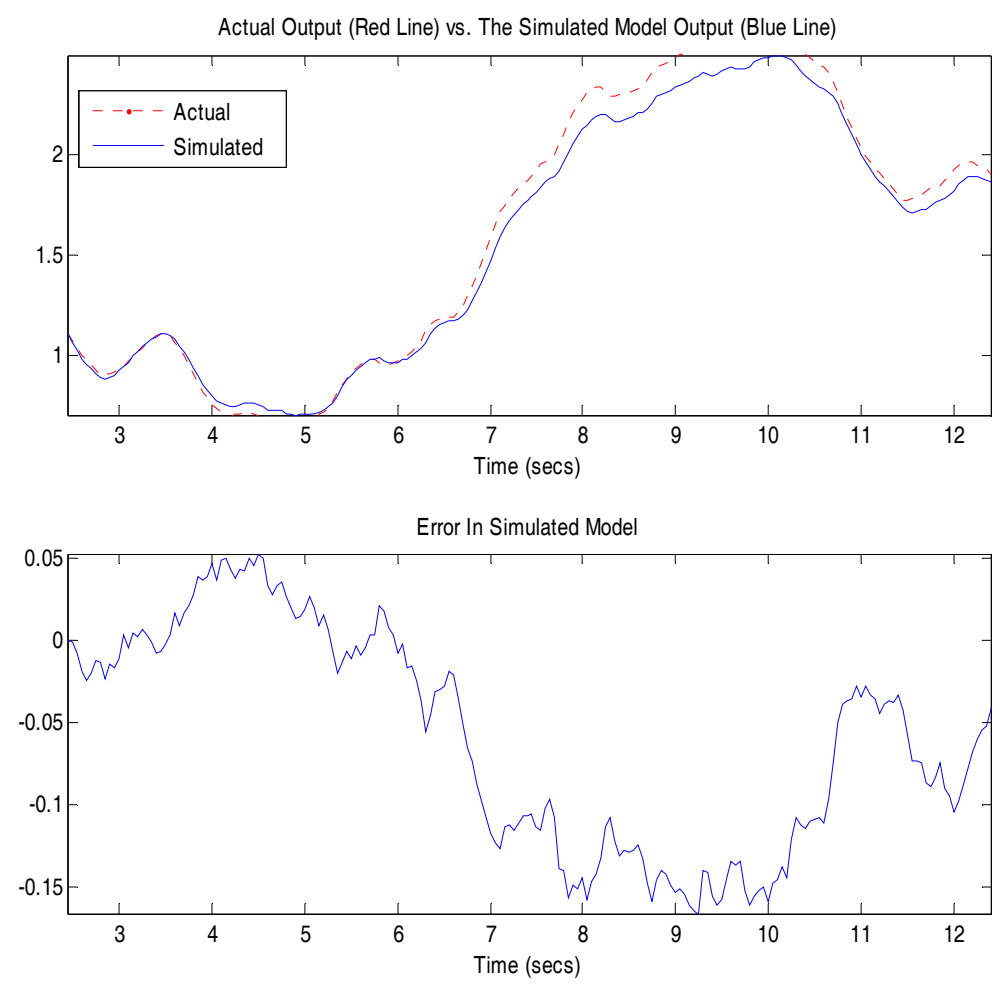

Fig. 10 Actual output is blue and simulated model output is red 


\section{Calculate the RMS error between the controllers}

In mathematics, the root mean square (abbreviated RMS or rms), also known as the quadratic mean, is a statistical measure of the magnitude of a varying quantity. It is especially useful when variates are positive and negative, e.g., sinusoids. RMS is used in various fields, including electrical engineering.

When two data sets one set from theoretical prediction and the other from actual measurement of some physical variable, for instance-are compared, the RMS of the pairwise differences of the two data sets. The corresponding formula for a continuous function (or waveform) $\mathrm{f}\left(\mathrm{t}\right.$ ) defined over the interval $T_{1} \leq t \leq T_{2}$ is:

$\mathrm{A}_{\mathrm{RMS}}=\sqrt{\frac{1}{T_{2}-T_{1}} \int_{T_{1}}^{T_{2}}[f(t)]^{2} d t}$

In this article, we obtain the error rate of the final amount response of each controller, we obtain the amounts RMS error as the Table 3.

TABLE 3. RMS ERROR FOR CONTROLLERS

\begin{tabular}{|l|l|}
\hline & RMS \\
\hline FUZZY controller & 1.057 \\
\hline KALMAN Filter & 1.123 \\
\hline LQR controller & 2.285 \\
\hline PID controller & 2.648 \\
\hline
\end{tabular}

As shown, fuzzy controller proposed have minimum RMS.

\section{MEASUREMENT AND PROCESS NOISE}

We consider here the common case of noisy sensor measurements. There are many sources of noise in such measurements. For example, each type of sensor has fundamental limitations related to the associated physical medium, and when pushing the envelope of these limitations the signals are typically degraded. In addition, some amount of random electrical noise is added to the signal via the sensor and the electrical circuits. The time-varying ratio of "pure" signal to the electrical noise continuously affects the quantity and quality of the information. The result is that information obtained from any one sensor must be quailed as it is interpreted as part of an overall sequence of estimates, and analytical measurement models typically incorporate some notion of random measurement noise or uncertainty as shown fig. 11.

There is the additional problem that the actual state transform model is completely unknown. While we can make predictions over relatively short intervals using models based on recent state transforms, such predictions assume that the transforms are predictable, which is not always the case. The result is that like sensor information, ongoing estimates of the state must be quailed as they are combined with measurements in an overall sequence of estimates. In addition, process models typically incorporate some notion of random motion or uncertainty as shown Figure11.

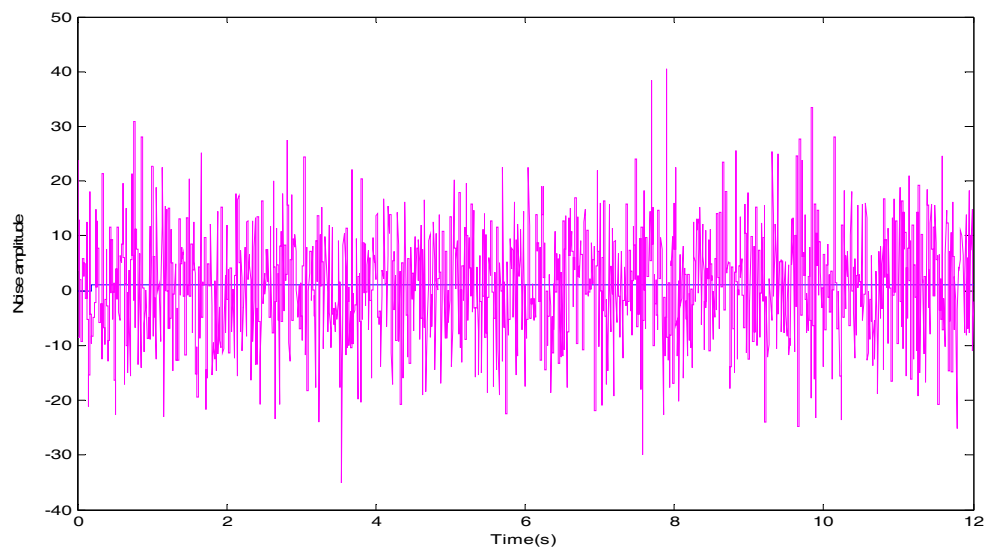


Fig. 11 Noise apply to pitch system

\section{KALMAN FILTER}

The Kalman filter is a mathematical power tool that is playing an increasingly important role in computer graphics as we include sensing of the real world in our systems.

In pitch system, the Kalman Filter is used to tracking Step response despite the severe disturbance on pitch system.

$$
\begin{aligned}
& \hat{x}[n \mid n]=\hat{x}[n \mid n-1]+K[n]\left(Z_{v}[n]-C \hat{x}[n \mid n-1]\right) \\
& M[n]=P[n \mid n-1] C^{T}\left(R[n]+C P[n \mid n-1] C^{T}\right)^{-1} \\
& P[n \mid n]=(I-K[n] C) P[n \mid n-1] \\
& \tilde{Z}[n]=C x[n \mid n]
\end{aligned}
$$

The Kalman filter addresses the general problem of trying to estimate the state of a discrete-time controlled process that is governed by the linear stochastic difference equation $x \in \Re^{n}$.

The Kalman filter is a set of mathematical equations that provides an efficient computational (recursive) solution of the least- squares method.

In this paper, it has been used from kalman filter for pursuit of step response despite disturbance. Error results are shown in Table 3.

The purpose of using Kalman filter is evaluation of the ability to track the input while existing the white noise in the system. The simulations prove the proper tracking performance of the fuzzy controller.

\section{Simulation}

The previous section, we introduced the controllers that used to control the processes. As expected, the fuzzy controller compared to other controllers, despite the perturbation (which can be caused by rain, storm, etc.), had more resistance and was more stable in the screw system. To demonstrate the robustness of this controller, very severe disturbances with high-amplitude have been applied to the system. Finally, the simulated output, after applying the high-amplitude white noise as the perturbation and step as input in the time domain, is figured in Fig. 12.

The proposed control schemes have been implemented within simulation environment in Matlab and Simulink in Fig. 13.

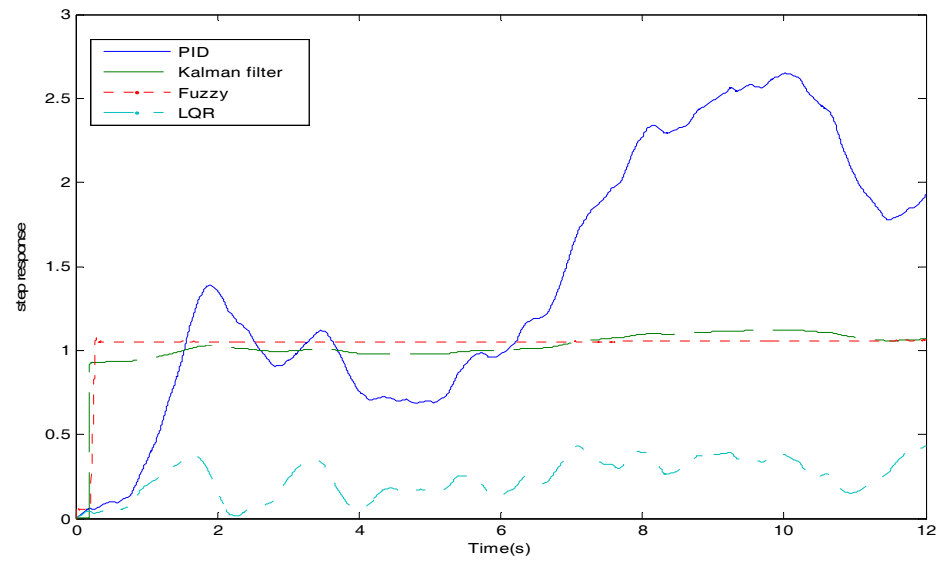

Fig.12 Step response and compare controllers together. 
Matlab/Simulink model block diagram of pitch control system used in this work is shown in Figure 13 presented.

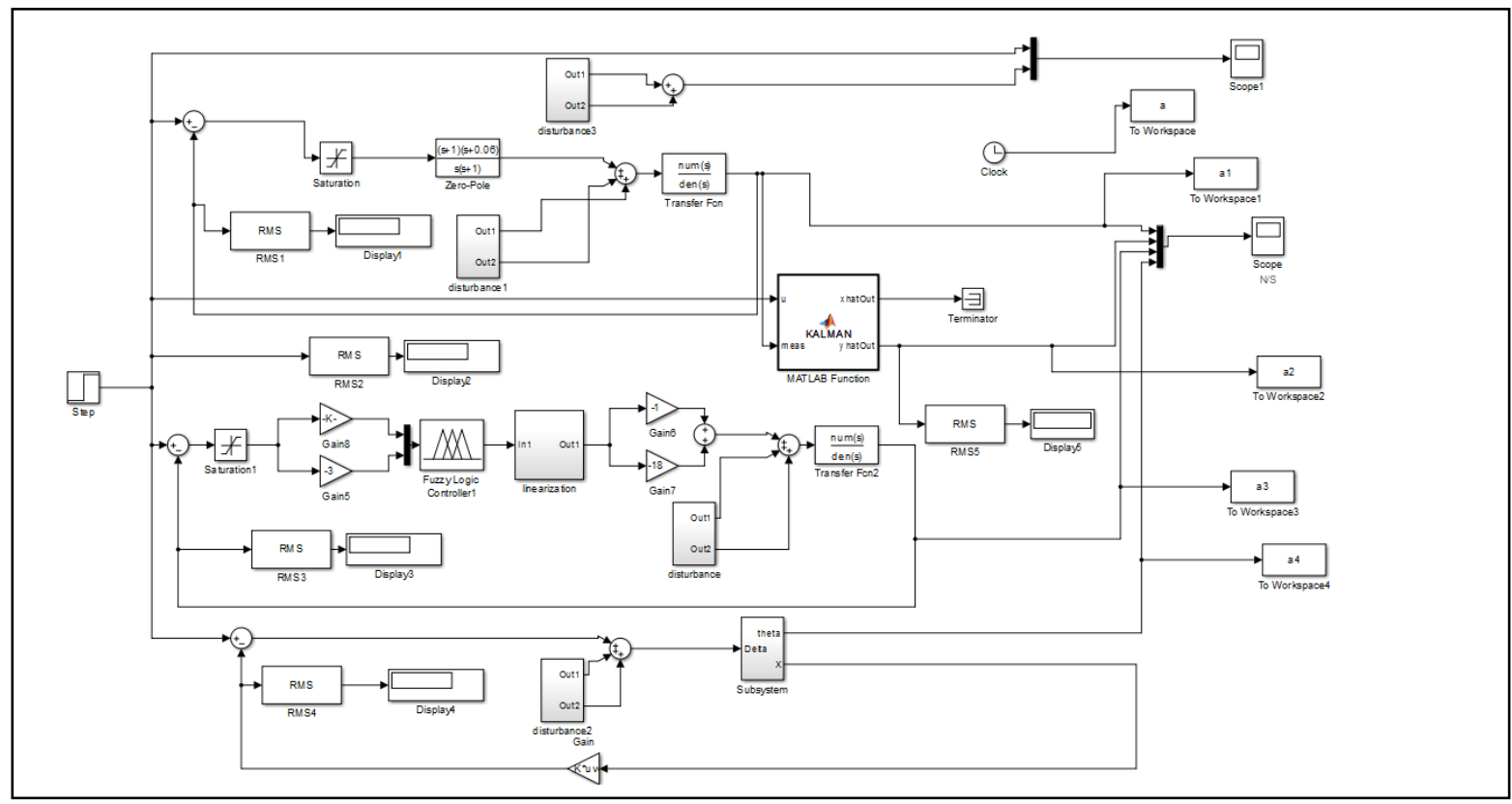

Figure13. Simulink model for pitch control system by types controllers.

\section{CONCLUSIONS}

A new control approach to pitch-rate command tracking off lighter aircraft has been proposed in this paper. Modelling is done on an aircraft pitch control and fuzzy controller is proposed successfully. The proposed control schemes have been implemented within simulation environment in Matlab and Simulink. Performance of the control schemes has been evaluated in term of time domain specification. The results obtained, demonstrate that the effect of the disturbances in the system can successfully be handled by fuzzy controller. Based on the results, the system responses indicate the performance of pitch control system using fuzzy controller has been improved and satisfied compared to LQR and PID For comparison of controller performance, the response for pitch control of an aircraft system using LQR and PID controller are shown with overall response controllers. The results clearly shows that Fuzzy controller has the best performance as compared to PID and LQR. Also in this paper, System's identification is a procedure for accurately characterizing the dynamic response behavior of a complete aircraft, of a subsystem, or of an individual component from measured data.

\section{References}

[1] N. Wahid, N. Hassan,M.F. Rahmat, "Application of Intelligent Controller in Feed-back Control Loop for Aircraft Pitch Control", Australian Journal of Basic and Applied Scen-ces 2011.

[2] J.K. Shiau, D.M. Ma, "An Autopilot Design for the Longitudinal Dynamics of a Low Speed Experimental UAV using Two Time Scale Cascade Decomposition", Transaction of the Canadian Society for Mechanical Engineering, Vol. 33, No. 3, 2009. 
[3] M. Myint, H.K. Oo, Z.M. Naing and Y.M Myint, "PID Controller for Stability of Piper Cherokee's Pitch Displacement using MATLAB", International Conference on Sustainable Development: Issues and prospects for the GMS, China, 2008.

[4] M. Zugaj, J.J. Narkiewicz, "Autopilot supported by Nonlinear Model Following Reconfigurable Flight Control System”, Journal of Aerospace Engineering, Vol. 23, 2010, No. 4, pp. 339-347.

[5] Khaleel Qutbodin, "Merging Autopilot/Flight Control and Navigation-Flight Management Systems", American Journal of Engineering and Applied Sciences, 2010, 629-630.

[6] N. Wahid, M.F. Rahmat, K. Jusoff, "ComparativeAssesment using LQR and Fuzzy Logic Controller for a Pitch Control System", European Journal of Scientific Research, Vol. 42, 2010, No. 2, pp. $184-194$.

[7] Chen, F.C. and Khalil, H.K., "Two-Time-Scale Longitudinal Control of Airplanes Using Singular Perturbation", AIAA, Journal of Guidance, Navigation, and Control, Vol. 13, 1990, No. 6, pp. 952-960.

[8] EkprasitPromtun, Sridhar Seshagiri, "Sliding Mode Control of Pitch Rate of an F-16 Aircraft", International Journal on Applied Science, Engineering and Technology, Vol. 5, 2009, No. 5.

[9]Nurbaiti Wahid, Nurhaffizah Hassan, "Self-tuning Fuzzy PID Controller Design for Aircraft Pitch Contro", 2012 Third International Conference on Intelligent Systems Modelling and Simulation, 2012 IEEE.

[10]S. Kamalasadan andAdel A. Ghandakly, "A Neural Network Parallel Adaptive Controller for Fighter Aircraft Pitch-Rate Tracking", IEEE transaction on instrumentation d measure-ment , January 2011

[11]Ju Jiang, Mohamed S. Kamel, "Pitch Control of an Aircraft with Aggregated Reinforcement Learning Algorithms", Proceedings of International Joint Conference on Neural Networks, Orlando, Florida, USA, IEEE 2007.

[12] Kailash Krishnaswamy, George Papageorgiou, "Analysis Of Aircraft Pitch Axis Stability Augmentation System Using Sum Of Squares Optimization", 2005 American Control Conference Intelligent Computation Technology and Automation, 2009 IEEE.

[13]Shuguo Liang, Xiaoping Chen, Bo Zhu, "A Non-overshooting Pitch-Angle Regulator for Aircraft with Conventional", Aerodynamic Configuration, 2012 Fifth International Conference on Intelligent Computation Technology and Automation, transaction 2012 IEEE.

[14]Dinesh Kumar. M, "Design of Modern and Classical Controllers For Navion Aircraft Pitch Control System", International Conference on Computing and Control Engineering (ICCCE 2012April, 2012.

[15] Yanhong Zhang, Zhongqiao Zheng, "Research on the parameters self-tuning fuzzy PID controller", 2009 Second International Symposium on Knowledge Acquisition and Modeling, IEEE 2009.

[16]Zheng LI, "Intelligent Fuzzy Immune PID Controller Design for Multivariable Process Control System", Proceedings of the 8th World Congress on Intelligent Control and Automation July 2010 IEEE.

[17]Yuman Yuan, Yuguang Feng, Wenjin Gu, "Fuzzy Model Reference Learning Control for Aircraft Pitch Autopilot Design", 2004 8th International Conference on Control, Automation. Robotics and Vision China, 6-9th December 2004, IEEE. 
[18]Mark B. Tischler, "System Identification Methods for Aircraft Flight Control Development and Validation", Aero flight dynamics, Directorate, U.S. Army ATCOM, Ames Research Center, Moffett Field, California, October 1995.

[19]Nurbaiti Wahid, Pitch Control System Using LQR and Fuzzy Logic Controller, 2010 IEEE Symposium on Industrial Electronics, Malaysia. 